\title{
USING POLYMERASE CHAIN REACTION IN DIRECT DETECTION OF MYCOPLASAMA GALLISEPTICUM AND MYCOPLASMA SYNOVIAE INFECTIONS IN BROILER BREEDER FLOCKS IN HAMA PROVINCE IN SYRIA
}

\author{
H. ALREFAIE ${ }^{*}$ and S. IBRAHIM** \\ * PhD student, Faculty of Vet Medicine, Albaath Univ, Hama, Syria. \\ ** Assistant professor of Microbiology Department, Faculty of Vet Medicine, Albaath Univ, Hama, Syria. \\ Email: hamid77ali@hotmail.com and hamid77ali@yahoo.com
}

\section{ABSTACT}

Received at: $27 / 5 / 2013$

Mycoplasama gallisepticum (MG) and Mycoplasma Synoviae (MS) are important avian pathogens which cause respiratory diseases resulting in large economic losses in Syria and world-wide poultry industry. The objective of this

Accepted: 25/6/2013 study is using multiplex polymerase chain reaction for direct detection of these agents from respiratory infections in broiler breeder flocks at Hama Province in Syria. For this purpose, 203 tracheal swabs were collected from birds which belonging to 29 flocks suffered from respiratory symptoms during the continued period between May 2011 and May 2012. The results revealed that 27 flocks (93\%) were infected by these species (16 mixed infections and 11 single infections). The number of infected flocks with MG was 25 flocks and MG prevalence in these flocks was $86 \%$. While the number of infected flocks with MS was 18 flocks and MS prevalence in these flocks was $72 \%$. Regardless of the flocks which belonging to them the studied samples, the results showed that $128(63 \%)$ birds were infected with MG and MS (66 mixed infections and 64 single infections); 119 birds were infected with $M G$, MG prevalence in the studied birds was $59 \%$ and 75 birds were infected with MS, MS prevalence in the studied birds was $37 \%$.

Key words: multiplex polymerase chain reaction, direct detection, Mycoplasma gallisepticum, Mycoplasma synoviae, broiler breeder flocks.
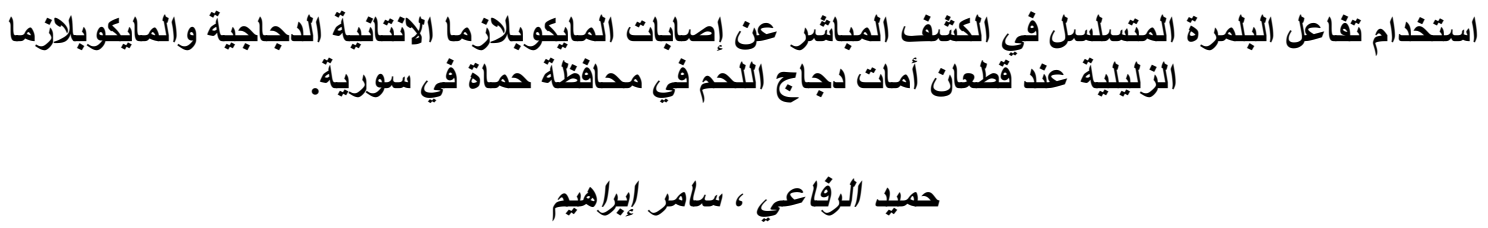

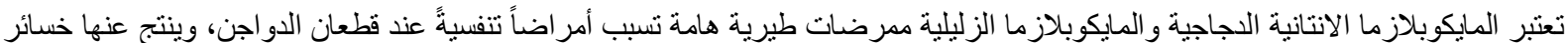

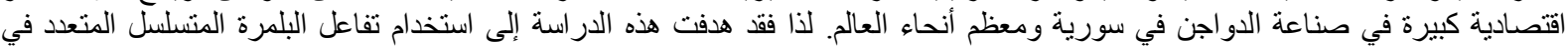

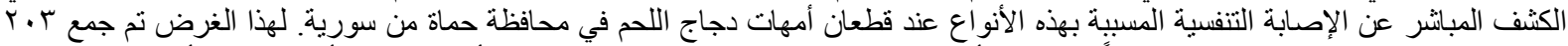

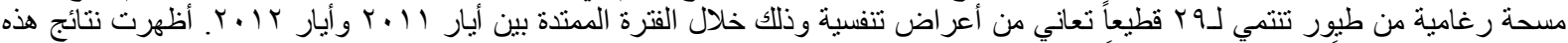

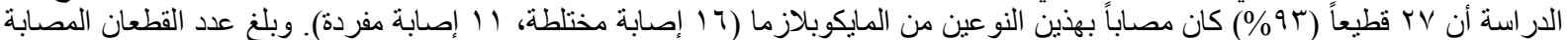

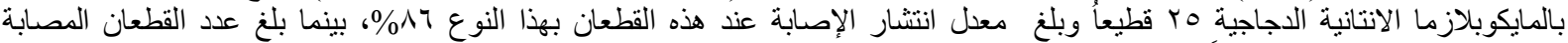

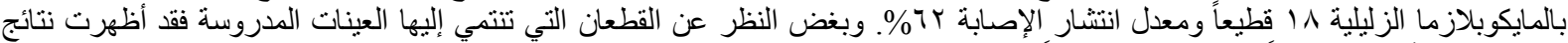

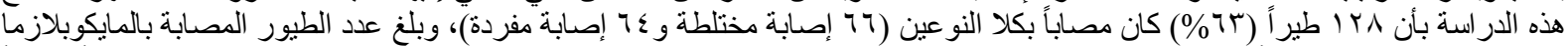

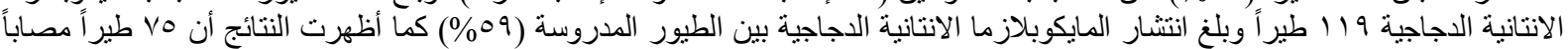

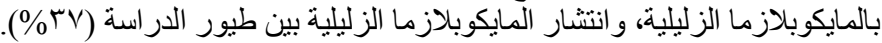

الكلمات المفتاحية: تفاعل البلمرة المتسلسل المتعدد، الكثف المباثر، المايكوبلازما الانتانية الدجاجية، المايكوبلازما الزليلية، قطعان دجاج التربية (أمهات دجاج اللحم). (المغاء). 


\section{INTRODUCTION}

المقدمـة

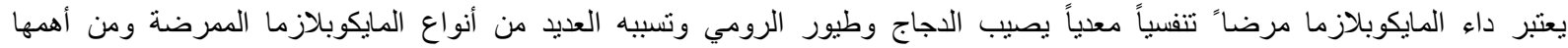

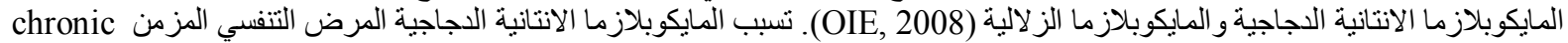
respiratory disease (CRD)

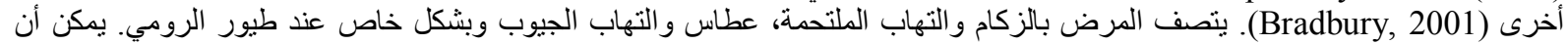

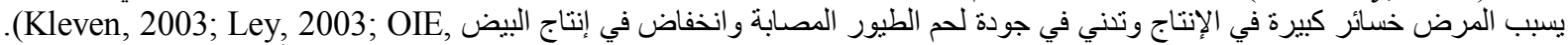

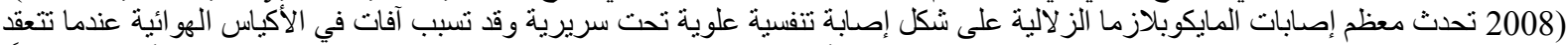

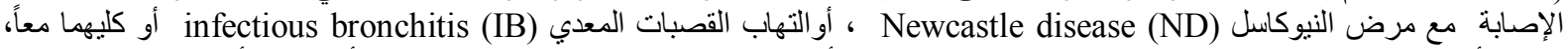

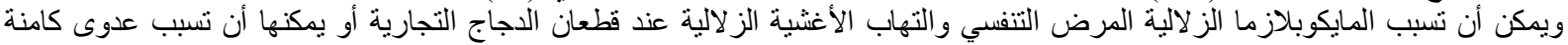
(Kleven, 2003; Ley, 2003; OIE, 2008)

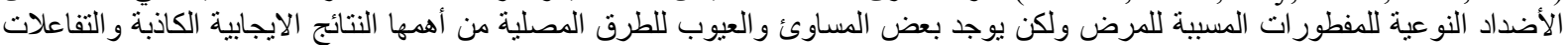

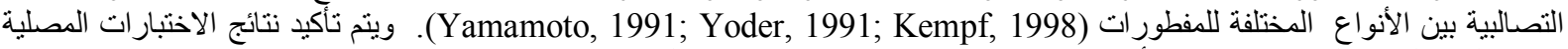

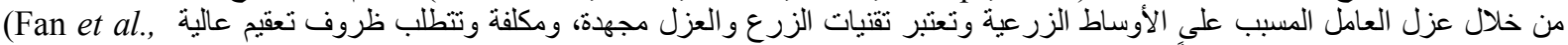

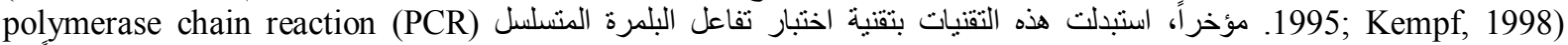

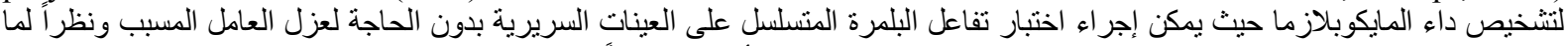

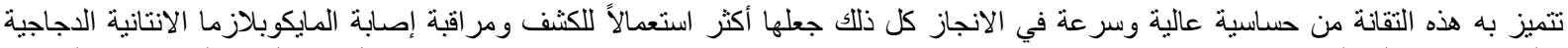

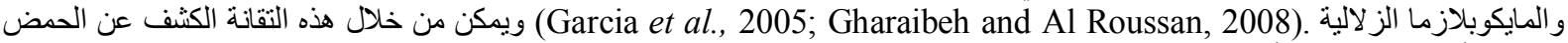

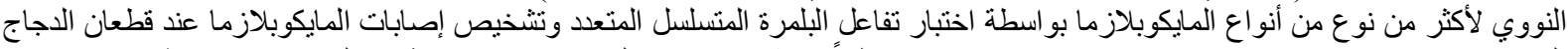

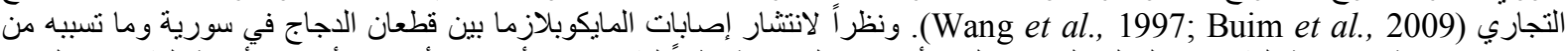

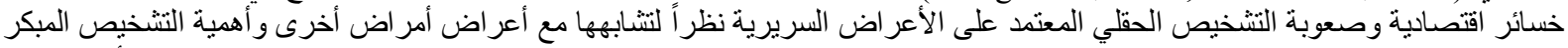

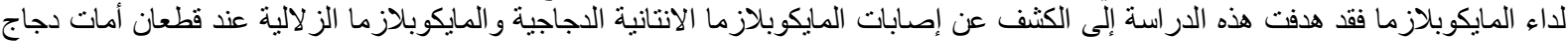

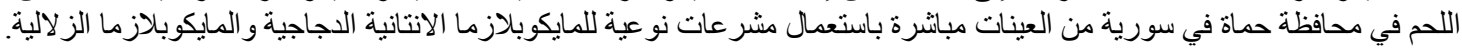

\section{MATERIALS and METHODS}

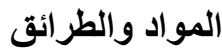

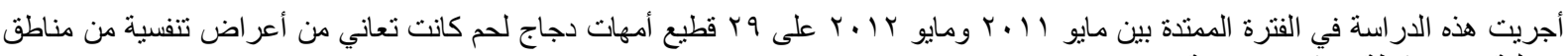
مختلفة من محافظة حماة في سورية.

جمع العينات Sampling

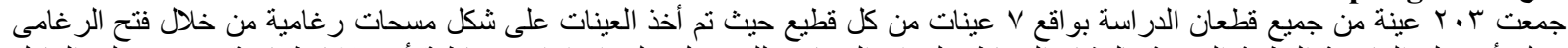

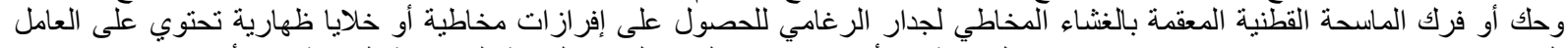

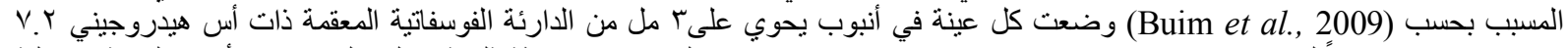

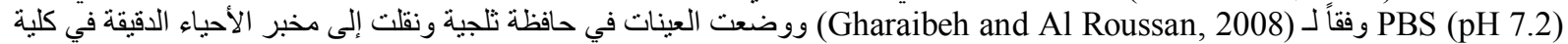

الطب البيطري.

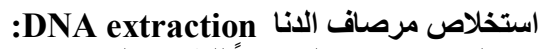

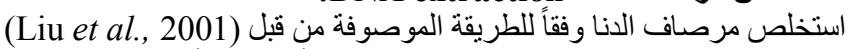

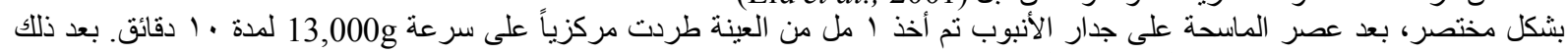

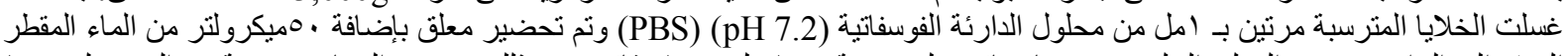

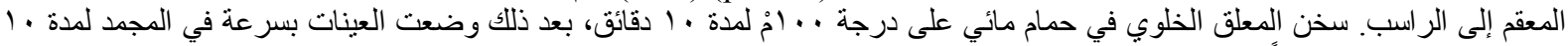

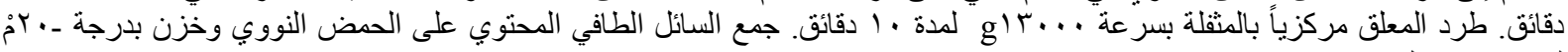
لحين الاستعمال.

إجراء تفاعل البلمرة المتسلسل المتعدد Multiplex PCR:

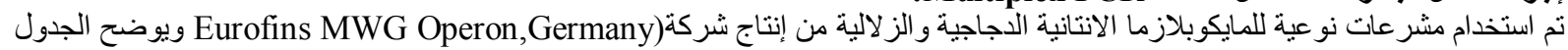
رقم (1) تسلسل هذه المشرعات

الجدول 1 : نسلسل المشر عات المستعملة في تفاعل البوليميريز المتسلسل المتعدد وحجم المنتجات.

\begin{tabular}{llll}
\hline Primersa & Sequence & Product & Reference \\
\hline MG-f & GAGCTAATCTGTAAAGTTGGTC & $185 \mathrm{pb}$ & Lauerman, 1998 \\
\cline { 1 - 2 } MG-r & GCTTCCTTGCGGTTAGCAAC & \\
\hline MS-f & GAGAAGCAAAATAGTGATATCA & \multirow{2}{*}{$207 \mathrm{pb}$} & Lauerman, 1998 \\
\cline { 1 - 2 } MS-r & CAGTCGTCTCCGAAGTTAACAA & & \\
\hline
\end{tabular}

$\mathrm{f}=$ forward, $\mathrm{r}=$ reverse. 
كما استعلت عتيدة خاصة بتفاعل البولميريز من إنتاج شركة كياجن PCR core kit( QIAGEN, Germany) أجري الاختبار وفقاً لـ (OIE,2008)

$10 \times$ PCR Buffer $\mathrm{dNTP}(10 \mathrm{mM})$

$\operatorname{MGF}(20 \mathrm{pmole} / \mu \mathrm{l})$

$\operatorname{MGR}(20 \mathrm{pmole} / \mu \mathrm{l})$

MS F $(20$ pmole/ $\mu$ l)

MS R $(20 \mathrm{pmole} / \mu \mathrm{l})$

$\operatorname{Taq}(5 \mathrm{U} / \mu \mathrm{l})$

$\mathrm{MgCl}_{2}$

H2O Ultra-pure

Template DNA

$$
\begin{aligned}
& \text { دارئة الاختبار } \quad \text { د } 5.00
\end{aligned}
$$

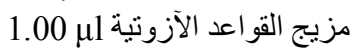

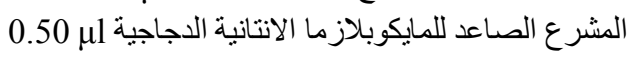

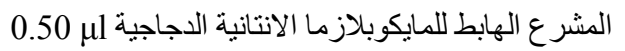

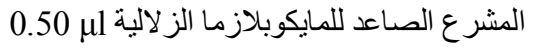

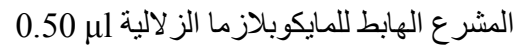

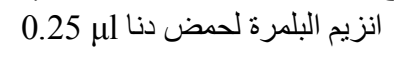

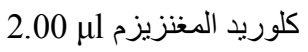

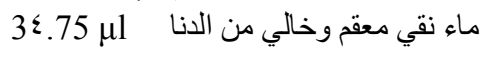

مرصاف الدنا البنانا

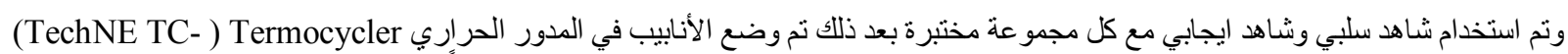

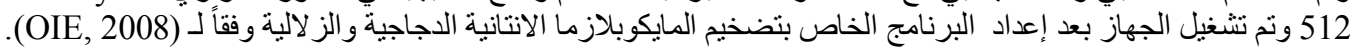

الجدول رقم ؟ّ: برنامج المدور الحراري للكثف عن المايكوبلازما الانتانية الدجاجية والمايكوبلازما الز لالية

\begin{tabular}{|c|c|c|c|}
\hline عدد الدورات & 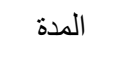 & درجة الحرارة & ل لمرحلة \\
\hline 1 & 2 دقيقة & 94 & Initial Denaturation \\
\hline \multirow[t]{3}{*}{40 دورة } & 30 ثنانية & 94 & Denaturation \\
\hline & 30 ثانية & 55 & Annealing \\
\hline & 1 دقيقة & 72 & Extension \\
\hline 1 دورة & 1 دقائق & ? 72 & Final-Extension \\
\hline
\end{tabular}

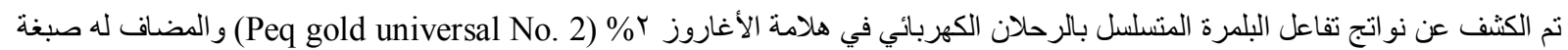

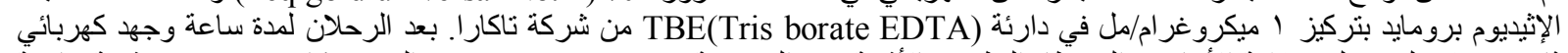

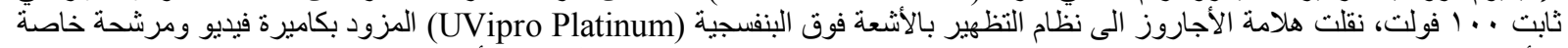

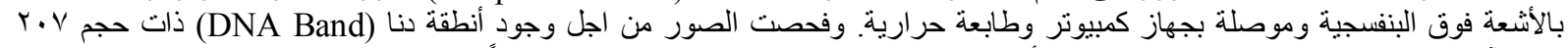

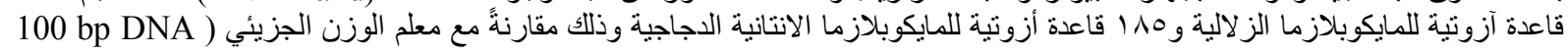
.(Ladder, PeqLab

\section{RESULTS}

$$
\text { النتائــجج }
$$

أظهرت نتائج اختبار تناعل البلمرة المتسلسل المتعدد المستخدم في هذه الدراسة في الكثف عن المايكوبلازما الانتانية الدجاجية والمايكوبلازما

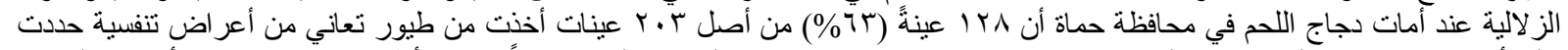

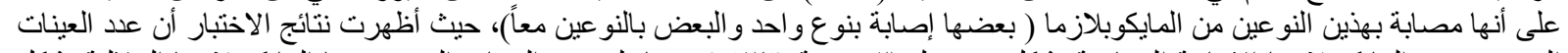

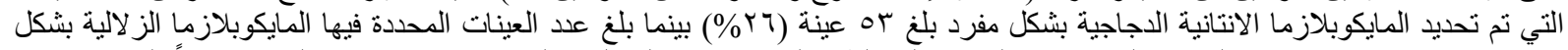

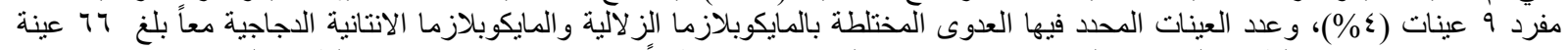

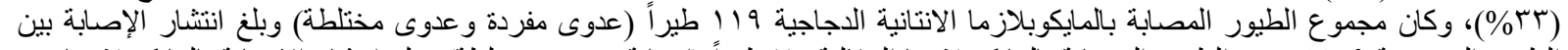

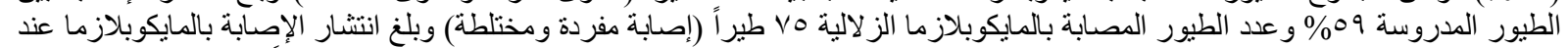

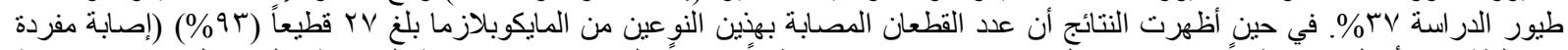

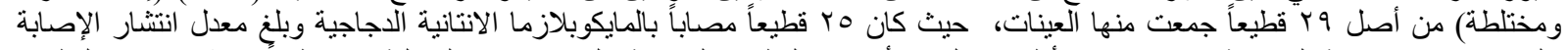

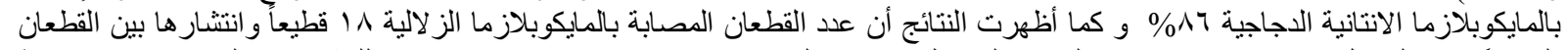

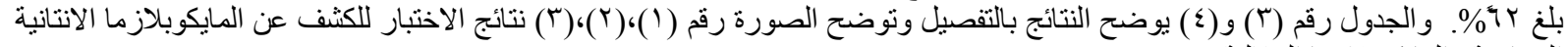
الدجاجية والمايكوبلازما الزلالية. 
$\underline{\text { Assiut Vet. Med. J. Vol. } 59 \text { No. } 138 \text { July } 2013}$

الجدول رقم ץ : نتائج اختبار PCR لانتشار المايكوبلازما الانتانية الدجاجية والمايكوبلازما الز لالية في العينات المأخوذة من أمات دجاج اللحم في

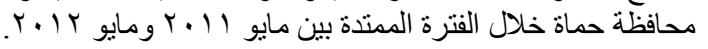

\begin{tabular}{|c|c|c|c|c|}
\hline \multicolumn{2}{|c|}{ العينات السلبية لاختبار الـPCR } & \multicolumn{2}{|c|}{ العينات الايجابية لاختبار الـPCR } & \multirow{2}{*}{ العامل الممرض } \\
\hline النسبة المئوية & 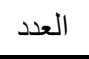 & النسبة المئوية & العدد & \\
\hline 74 & 150 & 26 & 53 & مايكو بلازما انتانية دجاجية \\
\hline 96 & 194 & 4.4 & 9 & مايكو بلازماز للالية \\
\hline 67 & 137 & 33 & 66 & عدوى مختلطة \\
\hline 41 & 84 & 59 & 119 & مجموع م.الانتانية الدجاجية \\
\hline 63 & 128 & 37 & 75 & مجموع م. الز لالية \\
\hline
\end{tabular}

الجدول رقم ع : نتائج اختبار PCR لانتثار المايكو بلازما الانتانية الدجاجية والمايكوبلازما الز لالية في قطعان أمات دجاج اللحم في محافظة حماة

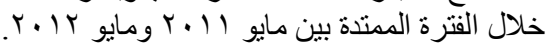

\begin{tabular}{|c|c|c|c|c|}
\hline \multicolumn{2}{|c|}{ القعطعان السليية لاختبار الـPCR } & \multicolumn{2}{|c|}{ القطعان الايجابية لاختبار الـPCR } & \multirow[t]{2}{*}{ العامل الممرض } \\
\hline النسبة المئوية & العدد ال العد & النسبة المئوية & 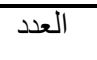 & \\
\hline 69 & 20 & 31 & 9 & مايكو بلازما انتانية دجاجية \\
\hline 93 & 27 & 7 & 2 & مايكو بلازما زلالية \\
\hline 45 & 13 & 55 & 16 & عدوى مختلطة \\
\hline 14 & 4 & 86 & 25 & مجموع م. الانتانية الاجاجية \\
\hline 38 & 11 & 62 & 18 & مجموع م. الزليلية \\
\hline
\end{tabular}

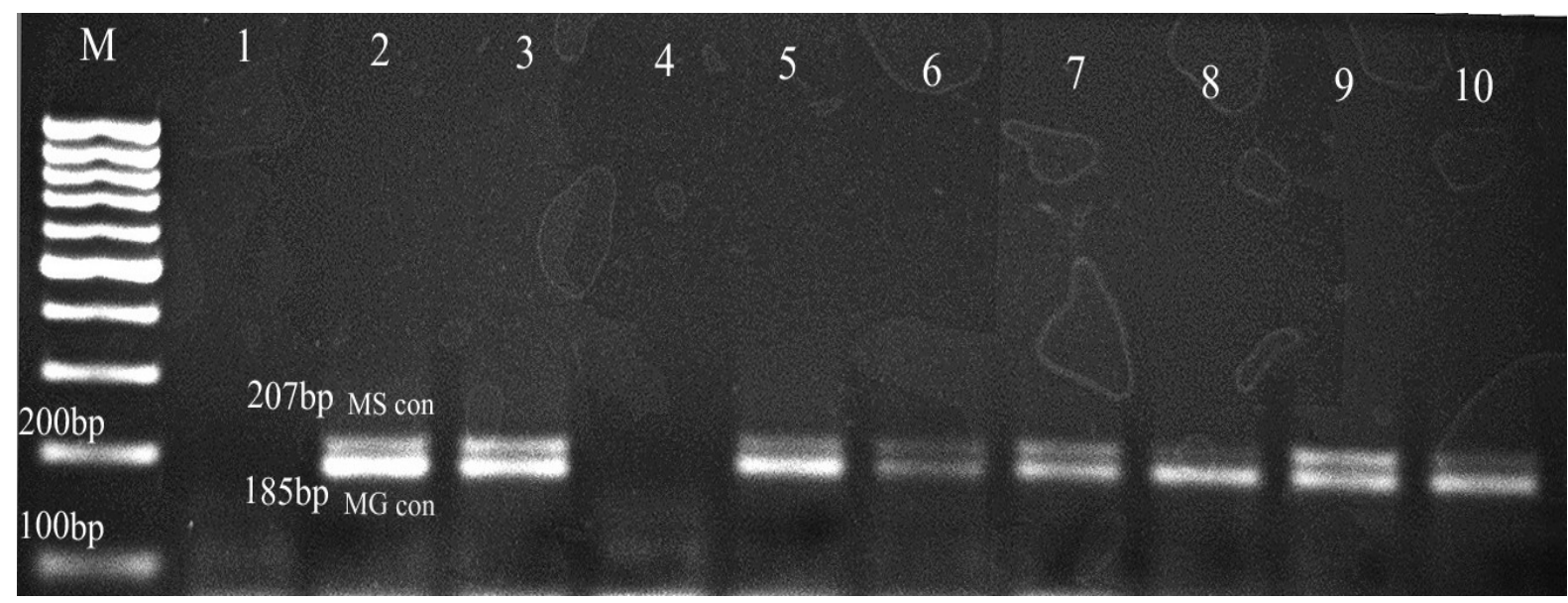

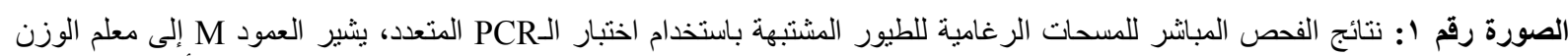

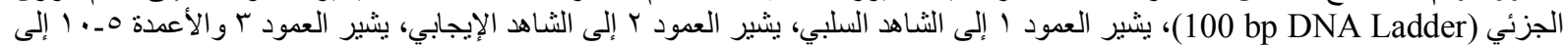

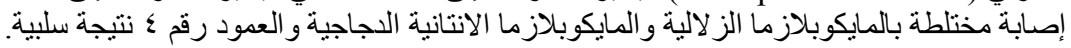




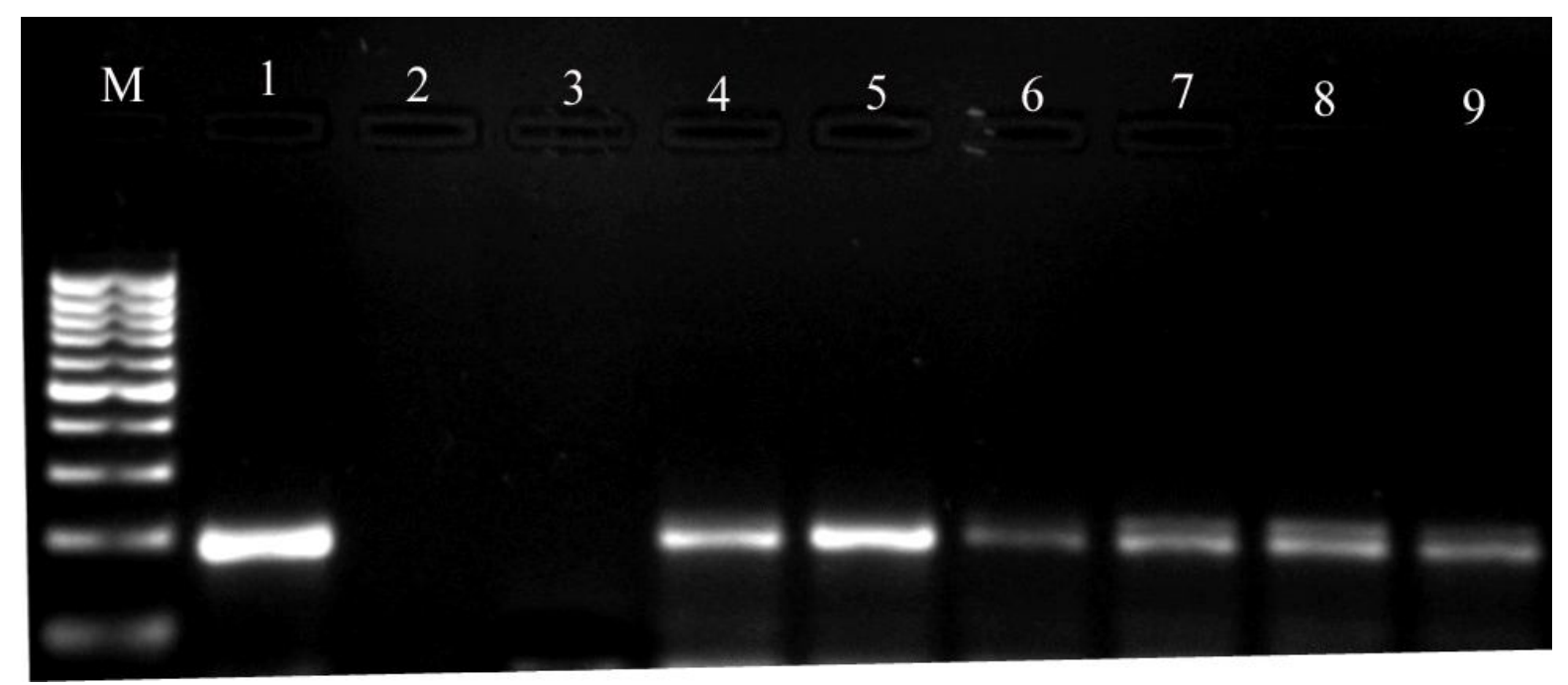

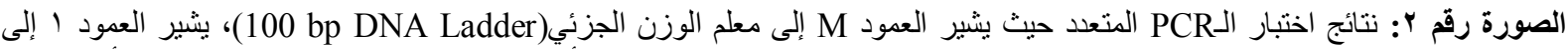

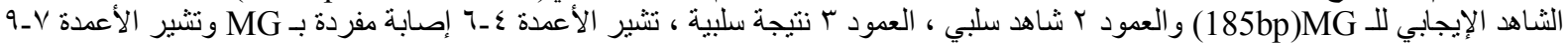

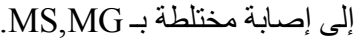

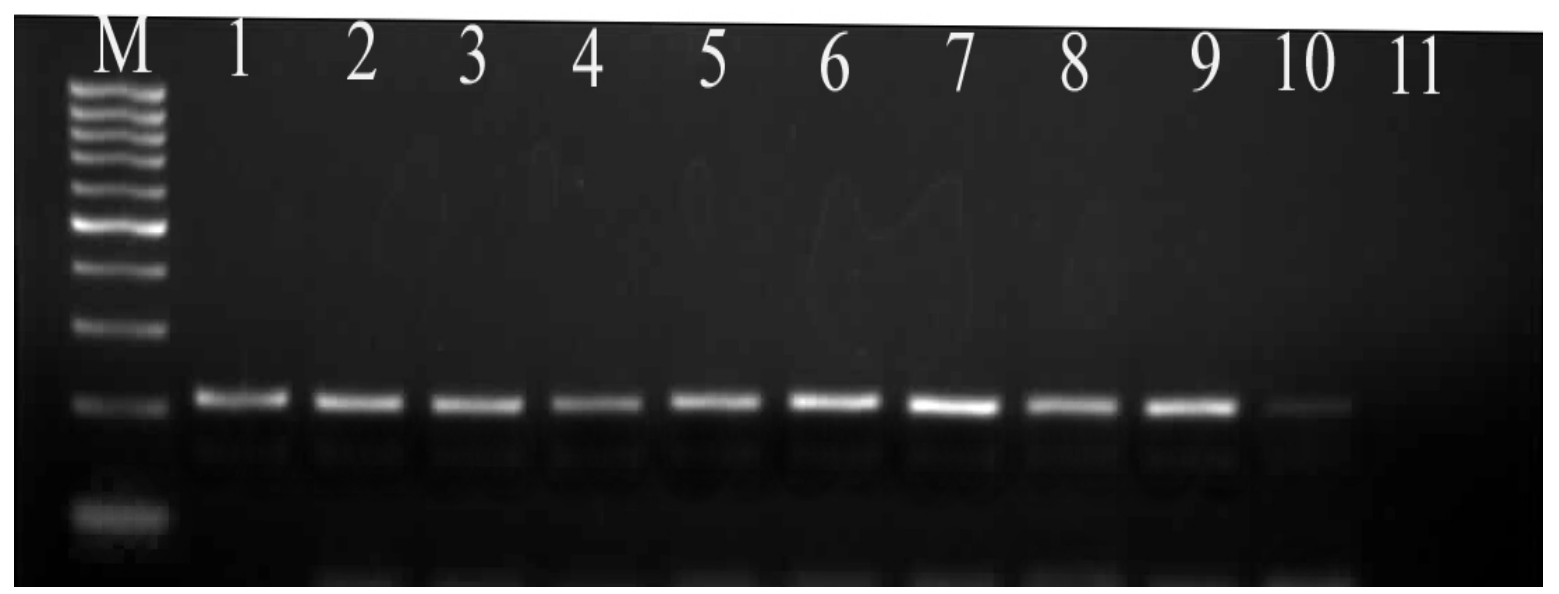

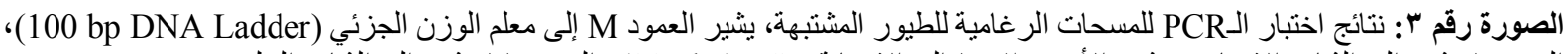

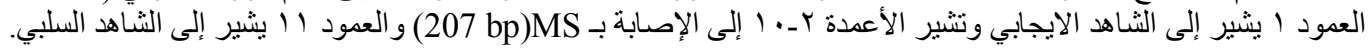

\section{DISCUSSION المناقثة}

تعتبر المايكوبلازما (المفطور ات) وخصوصاً المايكوبلازما الانتانية الاجاجية والمايكوبلازما الز لالية ممرضات طيرية هامة تسبب أمر اضاً تنفسيةً

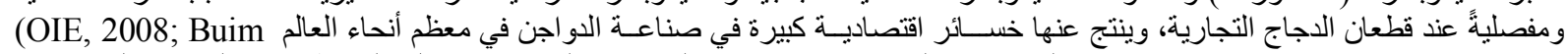

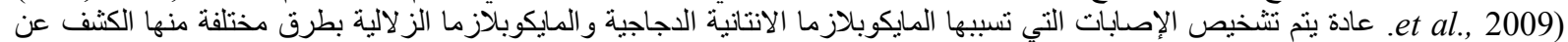

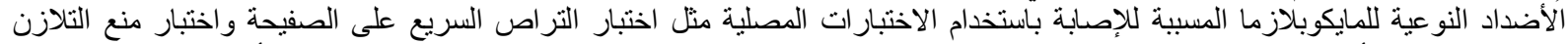

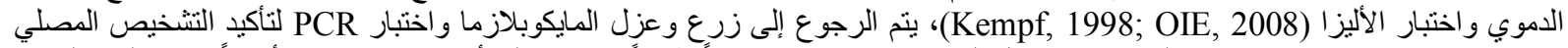

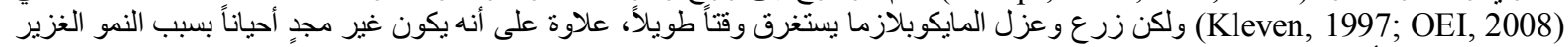

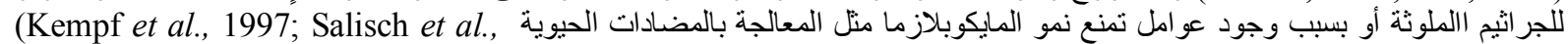
1998; Mekkes and Feberwee, 2005)

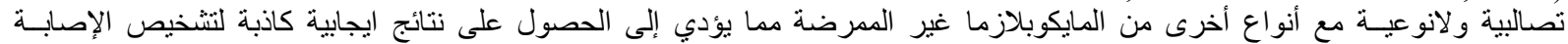

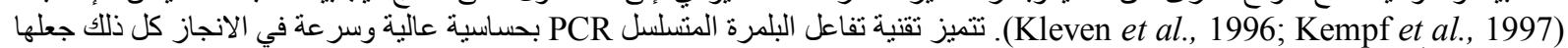

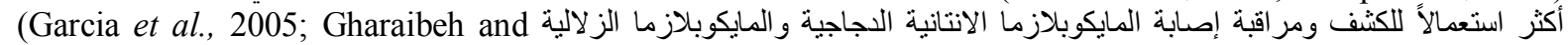

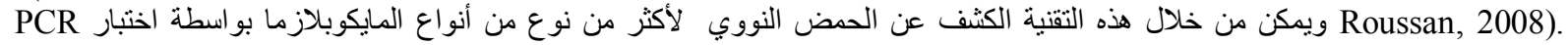

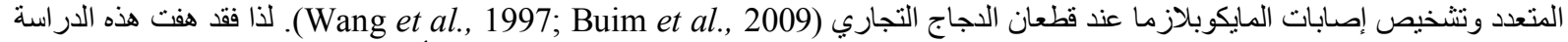

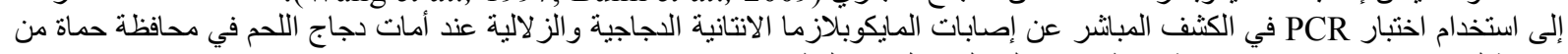

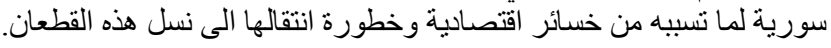




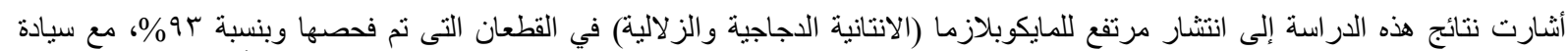

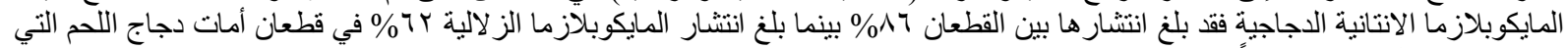

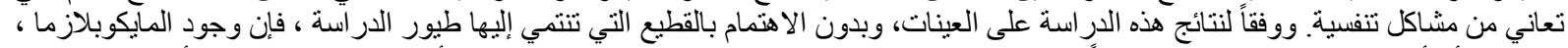

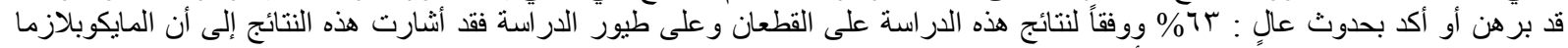

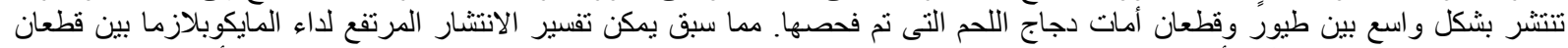

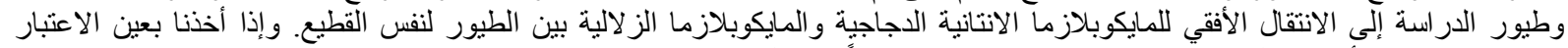

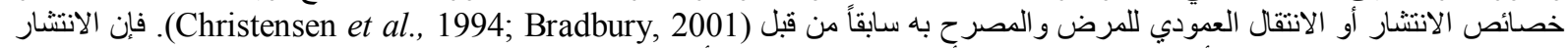

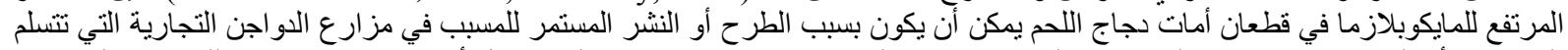

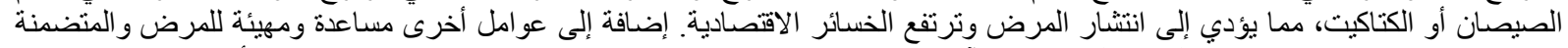

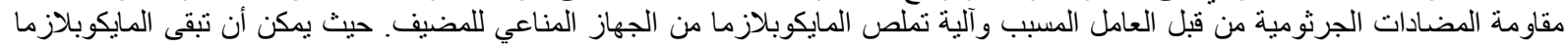

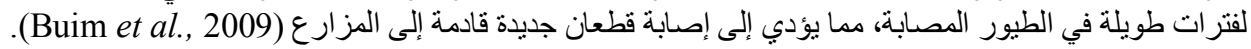

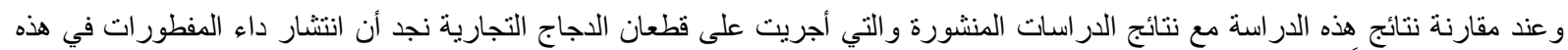

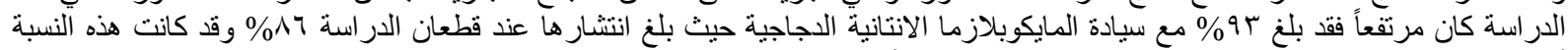

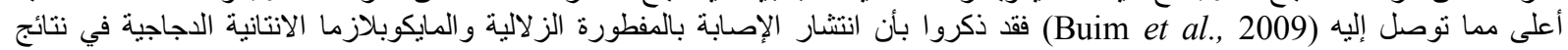

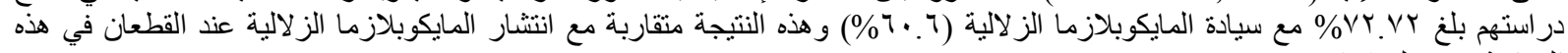

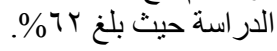

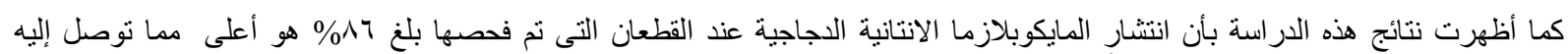
(Kahya et al., 2010)

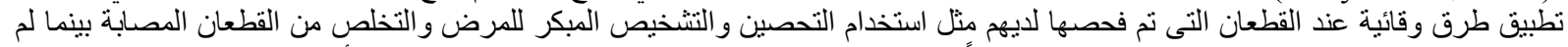

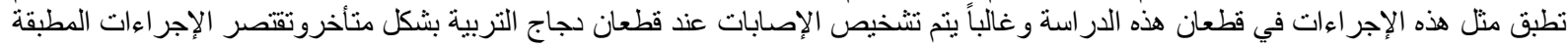
على المعالجة بالمضادات الحيوية.

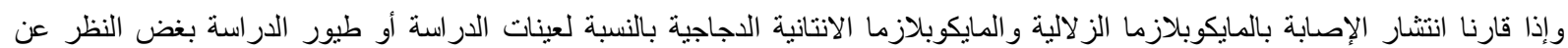

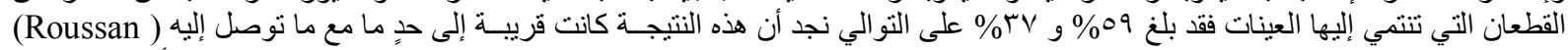

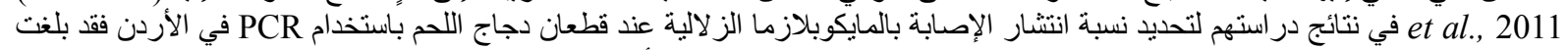

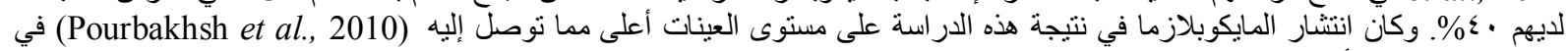

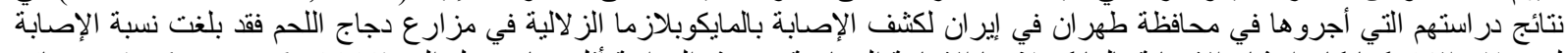

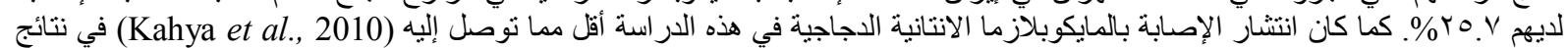

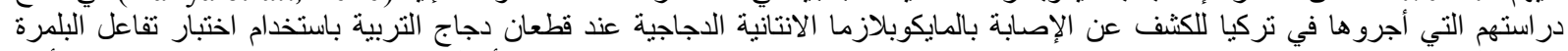

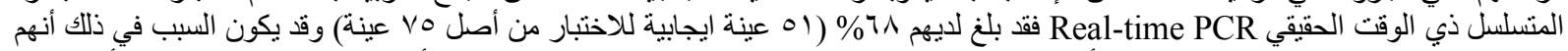

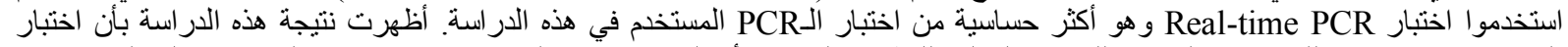

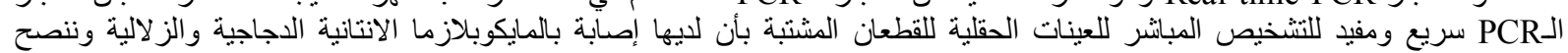
باستخدام هذه التقنية في الكثف المبكر عن إصابات المايكوبلازما عند قطعان للفئن دجاج التربية.

\section{REFERENCES}

Bradbury, J.M. (2001): Avian Mycoplasmosis. In: Poultry Diseases.5th ed. Jordan.D. and Raragher T. EDS. W.b. Sanders London, UK, 178-193.

Buim, M.R.; Mettifogo, E.; Timenetsky, J.; Kleven, S.; Antonio, J. and Ferreira, P. (2009): Epidemiological survey on Mycoplasma gallisepticum and M. synoviae by multiplex PCR in commercial poultry. Pesq. Vet. Bras. 29(7): 552-556.

Christensen, NH.; Yavari, CA.; Mc Bain, AJ. and Bradbury, JM. (1994): Investigation into the survival of Mycoplasma gallisepticum, Mycoplasma synoviae and Mycoplasma iowae on materials founds in poultry house environment. Avian pathol., 23: 127-143.

Fan, H.H.; Kleven, S.H.; Jackwood, M.W.; Johansson, K.E.; Pettersson, B. and Levisohn, S. (1995): Specks identification of avian mycoplasmas by polymerase chain reaction and restriction fragment length polymorphism assay. Avian Dis., 39: 307-398.

Garcia, M.; Ikuta, N.; Levisohn, S. and Kleven, S.H. (2005): Evaluation and comparison of various PCR methods for detection of Mycoplasma gallisepticum infection in chickens. Avian. Dis., 49: 125-32.

Gharaibeh, S. and Roussan, D.Al (2008): The Use of Molecular Techniques in Isolation and Characterization of Mycoplasma gallisepticum from Commercial Chickens in Jordan. Int. J. Poult. Sci., 7: 28-35.

Kahya, S.A.; Temelli, S.b.; Eyigor, A.b. and Carli, T.K.a. (2010): Real-time PCR culture and serology for the diagnosis of Mycoplasma gallisepticum in chicken breeder flocks. VET MIC. 4758 1-6.

Kempf, I. (1998): DNA amplification methods for diagnosis and epidemiological investigations of avian mycoplasmosis. Avian Pathol., 27: 7-14. 
Kempf, I.; Gesbert, F. and Guittet, M. (1997): Experimental infection of chickens with an atypical Mycoplasma gallisepticum strain: comparison of diagnostic methods. Res. Vet. Sci. 63, 211-213.

Kleven, S.H. (1997): Changing expectations in the control of Mycoplasma gallisepticum. Acta Vet. Hung. 45 , 299-305.

Kleven, S.H. (2003): Mycoplasma synoviae infection. In Y.M. Saif (Ed.), Diseases of Poultry, $11^{\text {th }}$ edn (pp. 756 1766). Ames: Iowa State University Press.

Kleven, S.H.; Jordan, F.T.W. and Bradbury, J.M. (1996): Avian Mycoplasmosis (Mycoplasma gallisepticum). In: Reichard, R. (Ed.), Manual of Standards for Diagnostic Tests and Vaccines. Office International Des Epizootics, Paris, France, pp. 512-521.

Ley, D.H. (2003): Mycoplasma gallisepticum Infection. In: Saif, Y.M., H.J. Barnes, J.R. Glisson, A.M. Fadly, L.R. McDougald and D.E. Swayne (Eds.). Diseases of Poult., 11th Edn. Iowa State Press, Ames, Iowa., pp:722-744.

Liu, T.; Garcia, M.; Levisohn, S.; Yogev, D. and Kleven, S. (2001): Molecular variability of the adhesionencoding Gene pvpA among Mycoplasma gallisepticum strains and its application in diagnosis. J. Clin. Microbiol., 39: 1882-1888.

Mekkes, D.R. and Feberwee, A. (2005): Real-time polymerase chain reaction for the qualitative and quantitative detection of Mycoplasma gallisepticum. Avian Pathol. 34, 348-354.

OIE (2008): Manual of diagnostic tests and vaccines for terrestrial animals, six ${ }^{\text {th }}$ ed. International des Epizooties (World Organization for Animal Health), Paris, p.486 (ISBN92-9044-510-6).

Pourbakhsh, S.A.; Shokri1, G.R.; Banani1, M.; Elhamnia, F. and Ashtari1, A. (2010): Detection of Mycoplasma synoviae infection in broiler breeder farms of Tehran province using PCR and culture methods. Archives of Razi Institute, Vol. 65, No. 2, 75-81.

Roussan, D.A.; Al-Rifai, R.H.; Khawaldeh, G.Y.; Totanji, W.S. and Shaheen, I(2011):Ornithobacteriumrhinotracheale and Mycoplasma synoviae in broiler chickens in Jordan. Rev. sci. tech. Off. int. Epiz., 30 (3); 931-937.

Salisch, H.; Hinz, K.H.; Graack, H.D. and Ryll, M. (1998): A comparison of a

commercial PCR-based test to culture methods for detection of Mycoplasma gallisepticum and Mycoplasma synoviae in concurrently infected chickens. Avian Pathol. 27, 142-147.

Wang, H.; Fadl, A.A. and Khan, M.I (1997): Multiplex PCR for avian pathogenic mycoplasmas. Mol. Cell. Probes, 11: 211-216.

Yamamoto, R. (1991): Mycoplasma meleagridis infection. In B.W. Calnek, C.W. Beard, H.J. Barnes, W.M. Reid $\&$ H.W. Yoder Jr (Eds). Diseases of Poultry, $9^{\text {th }}$ edn. (pp. 212-223).

Yoder, H.W.Jr (1991): Mycoplasma gallisepticum infection. In B.W.

Calnek, C.W. Beard; H.J. Barnes, W.M. Reid and H.W. Yoder Jr (Eds): Diseases of Poultry, $9^{\text {th }}$ edn. (pp. 198212) Ames: Iowa State University Press. 